\title{
PENGARUH PERIODE KONSERVASI DAN PERLAKUAN PRIMING TERHADAP PERKECAMBAHAN BENIH KESAMBI (Sleichera oleosa)
}

\author{
The Effect of Temporary Storage and Priming Treatment on the Germination on Kesambi \\ (Sleichera oleosa) Seeds
}

\author{
M. Zanzibar, Yulianti Bramasto dan/and Safrudin Mokodompit \\ Balai Penelitian Teknologi Perbenihan Bogor \\ Jl. Pakuan Ciheuleut PO. Box 105, Bogor - 16001 \\ Telp./Fax. (0251) 8327768
}

Naskah masuk : 24 Agustus 2008; Naskah diterima : 5 Agustus 2009

\begin{abstract}
Generally after harvesting, seed exceed the temporary storage or conservation periods. The periods of conservation is aimingat takingan optimum potency before they go through another proces, for example giving the priming treatment. The principle of priming is to activate the internal and external resources for maximizing seedling growth by regulating water absortion of embryo. The objective of this research was to measure the effect of conservation periods and priming on the germination capacity of kesambi seed. The experimental design this research is randomly comppetely factorial design, with the main factors are conservation periods $(A)$ and priming technique (B). There are four stages of the conservation periods, such as $0,4,8$ and 12 weeks at ambient room $\left(t=25^{\circ}-27^{\circ} \mathrm{C} ; \mathrm{RH}=80-90 \%\right)$ and the priming techniques were: control (without priming), hydration-dehydration by $\mathrm{H}_{2} \mathrm{O}, \mathrm{PEG} 600$ (at-5 and-10 bars), $\mathrm{KNO}_{3}$ (at - 5 and -10 bars) and matriconditioning by kitchen ash. The results showed that priming matriconditioning by kitchen ash was the best treatment to increasing the germination capacity of kesambi seed while the priming - osmoconditioning treatments by $P E G$ and $\mathrm{KNO}_{3}$ was destructive. It was proved that kesambi seeds need after ripening condition before germination.
\end{abstract}

Key words: dehydration, hydration, matriconditioning, osmoconditioning, kesambi seed

\begin{abstract}
ABSTRAK
Setelah pemanenan, umumnya benih mengalami penyimpanan sementara (periode konservasi). Periode konservasi bertujuan untuk mengkondisikan benih mencapai potensi optimum sebelum mendapatkan penanganan lanjutan, misalnya memberikan perlakuan priming. Prinsip priming adalah mengaktifkan sumber daya internal dan sumber daya eksternal dalam memaksimumkan pertumbuhan kecambah melalui laju pengaturan penyerapan air oleh embrio. Penelitian ini bertujuan mengetahui pengaruh periode konservasi dan perlakuan priming terhadap kemampuan perkecambahan benih kesambi. Penelitian dianalisis dengan rancangan acak lengkap faktorial, faktor utama adalah periode konservasi (A) dan priming (B). Periode konservasi terdiri dari : 0, 4, 8 dan 12 minggu pada suhu kamar $\left(\mathrm{t}=25^{\circ}-27^{\circ} \mathrm{C}\right.$, $\mathrm{RH}=80-90 \%$ ), sedangkan taraf priming adalah : tanpa priming (kontrol), hidrasi - dehidrasi dengan $\mathrm{H}_{2} \mathrm{O}$, PEG 6000 (- 5 dan - 10 bar), $\mathrm{KNO}_{3}$ (- 5 dan - 10 bar) dan abu gosok. Hasil penelitian menunjukkan bahwa priming-matriconditioning dengan abu gosok merupakan perlakuan terbaik meningkatkan kapasitas perkecambahan, sedangkan penggunaan PEG dan $\mathrm{KNO}_{3}$ berakibat buruk. Benih kesambi memiliki sifat pemasakan lanjutan (after ripening) sehingga membutuhkan penyimpanan sementara sebelum dikecambahkan.
\end{abstract}

Kata kunci: dehidrasi, hidrasi, matriconditioning, osmokonditioning, benih kesambi

\section{PENDAHULUAN}




\section{A. Latar Belakang}

Penyimpanan sementara atau periode konservasi (temporary storage) dimaksudkan mengkondisikan benih mencapai potensi optimum hingga dilakukan penanganan lanjutan (Schmidt, 2000). Selama periode tersebut kegiatan yang dapat dilakukan berupa pembuangan ranting/daun, penurunan kadar air benih/buah, pemeraman serta pemberian zat kimia penghambat perkecambahan.

Perlakuan priming yang tepat mampu meningkatkan potensi benih. Pada beberapa keadaan, perlakuan ini berfungsi sama dengan pemeraman, yaitu memperbaiki perkecambahan, daya simpan dan kinerja pertumbuhan di lapang. Menurut Murray dan Wilson (1987), priming merupakan perlakuan pendahuluan yang dapat mengontrol laju penyerapan air oleh embrio, peningkatan aktivitas mitokondria melalui biosintesis penting, mempertahankan ultra struktur sel sehingga benih lebih tahan terhadap tekanan serta merangsang pertumbuhan. Menurut Bailly et al. (1998), priming dapat memperbaiki kondisi fisiologi benih. Perbaikan tersebut meliputi, peningkatan perolehan daya berkecambah serta perkecambahan yang lebih cepat dan serempak. Metode priming dilakukan dengan dua cara, yaitu pengkondisian benih dalam larutan osmotikum (osmoconditioning) dan dalam media padatan basah (matriconditioning).

Benih kesambi memiliki kulit (testa) yang impermeabel terhadap air dan udara. Kulit yang impermeabel kerap kali dijumpai pada benih semi rekalsitran (Roberts, 1976), akan cepat kehilangan viabilitasnya bila dikeringkan secara berlebihan atau disimpan pada suhu dan kelembaban tinggi. Selain itu, kulit yang demikian sangat peka terhadap perlakuan invigorasi sehingga perlakuan priming selama periode konservasi berpeluang meningkatkan potensi perkecambahan pada benih kesambi.

\section{B. Tujuan}

Penelitian ini bertujuan mengetahui pengaruh periode konservasi dan priming terhadap perkecambahan benih kesambi.

\section{BAHAN DAN METODE}

\section{A. Bahan dan Alat}

Benih kesambi diperoleh dari KPH Lawu Ds. Bahan dan alat lainnya adalah $\mathrm{KNO}_{3}, \mathrm{PEG} 6000$, $\mathrm{H}_{2} \mathrm{O}$, abu gosok, media perkecambahan (tanah dan pasir), kain blacu, gelas piala, pengaduk, bak kecambah, sprayer, dan lain-lain.

\section{B. Metode Kerja}

Benih diekstraksi dengan cara basah, yaitu kumpulan buah dimasukkan ke dalam wadah yang berisi air dan pasir halus. Buah yang telah bercampur dengan pasir kemudian diremas-remas/digosok hingga daging buah terlepas dari kulit benih. Benih dikeringanginkan pada suhu kamar $\left(\mathrm{t}=25^{\circ}-27^{\circ} \mathrm{C}, \mathrm{RH}\right.$ $=80-90 \%$ ) selama 3 hari. Kadar air awal benih rata-rata $=13,00 \%$. Selanjutnya, benih dikemas dalam wadah kain blacu lalu disimpan sementara pada suhu kamar. Periode konservasi selama : 0, 4, 8 dan 12 minggu.

Setelah masing-masing periode konservasi dicapai kemudian dilakukan priming. Priming osmoconditioning menggunakan PEG 6000 (-5 dan -10 bar), $\mathrm{KNO}_{3}$ (-5 dan -10 bar) dan hidrasi-dehidrasi. Formula PEG 6000 dihitung berdasarkan rumus Michel (1988) sebagai berikut :

$$
\begin{aligned}
& \left\{4(5,16 ¥ \mathrm{~T} 560 ¥+16)^{0,5}\right\} \\
& {[\mathrm{PEG}]=} \\
& (2,5 \text { T } 280)
\end{aligned}
$$


dimana :

$$
\begin{aligned}
{[\mathrm{PEG}] } & \left.=\text { Konsentrasi PEG (gram } \mathrm{PEG} / \text { gram } \mathrm{H}_{2} \mathrm{O}\right) \\
¥ & =\text { Potensial osmotik larutan }(\text { bar }) \\
\mathrm{T} & =\text { Suhu ruangan }\left({ }^{\circ} \mathrm{C}\right) \\
1 \mathrm{Bar} & =10^{-1} \mathrm{Mpa}
\end{aligned}
$$

Formula $\mathrm{KNO}_{3}$ digunakan rumus Vant Holff dalam Wilkins (1990), yaitu :

$$
\mathrm{P}=\frac{-(\mathrm{m} / \mathrm{BM}) \mathrm{R} \mathrm{T}}{\mathrm{V}}
$$

dimana:

$$
\begin{aligned}
\mathrm{P} & =\text { Potensial osmotik } \\
\mathrm{m} & =\text { Massa } \mathrm{KNO}_{3}(\text { gram }) \\
\mathrm{T} & =\text { Suhu mutlak }\left({ }^{\circ} \mathrm{K}\right) \\
\mathrm{V} & =\text { Volume (liter) } \\
\mathrm{R} & =0,0821 \\
\mathrm{BM} & =\text { Berat molekul }
\end{aligned}
$$

Benih direndam dalam masing-masing larutan $\left(\mathrm{PEG}\right.$ dan $\left.\mathrm{KNO}_{3}\right)$ pada gelas piala tertutup, setiap 3 jam diaduk secara merata agar kebutuhan oksigen terpenuhi serta untuk mengontrol laju imbibisi. Perendaman dihentikan sehari sebelum radikel muncul (3 hari) lalu dikeringanginkan hingga mencapai berat awal (sebelum perendaman). Hidrasi - dehidrasi : merendam benih ke dalam air selama 12 jam dikeringanginkan selama 12 jam. Perlakuan yang sama diulang 3 kali.

Priming - matriconditioning : mencampur benih ke dalam abu gosok jenuh air selama 3 hari, setiap 3 jam campuran benih dan abu gosok diaduk seperti halnya perlakuan osmoconditioning. Perbandingan berat antara abu gosok : benih : air adalah 0,4:1:1 (Zanzibar dan Mokodompit, 2007).

Media tabur menggunakan campuran tanah dan pasir dengan perbandingan $1: 1(\mathrm{v} / \mathrm{v})$. Perkecambahan dilakukan di rumah kaca. Ulangan sebanyak 4 kali, masing-masing terdiri dari 25 butir.

\section{Rancangan Percobaan dan Analisis Data}

Penelitian ini dianalisis menggunakan rancangan acak lengkap pola faktorial (RAL). Model statistik adalah sebagai berikut:

dimana :

$$
Y_{i j}=u+A_{i}+B_{j}+A B_{i j}+E_{i j k}
$$

$\begin{aligned} \mathrm{Y}_{\mathrm{ij}} \quad= & \text { Nilai respon pengamatan } \\ \mathrm{u}= & \text { Nilai rata-rata umum } \\ \mathrm{A}_{\mathrm{i}}= & \text { Pengaruh faktor periode konservasi, terdiri dari: } \\ & \mathrm{a}_{1}=0 \text { minggu } \\ & \mathrm{a}_{2}=4 \text { minggu } \\ & \mathrm{a}_{3}=8 \text { minggu } \\ \quad & \mathrm{a}_{4}=12 \text { minggu } \\ \quad & \text { Pengaruh faktor priming, terdiri dari : } \\ & \mathrm{b}_{1}=\text { tanpa priming } \\ & \mathrm{b}_{2}=\text { hidrasi }- \text { dehidrasi dengan } \mathrm{H}_{2} \mathrm{O} \\ & \mathrm{b}_{3}=\text { PEG } 6000 \text { tekanan }-5 \text { bar } \\ & \mathrm{b}_{4}=\mathrm{PEG} 6000 \text { tekanan }-10 \text { bar } \\ & \mathrm{b}_{5}=\mathrm{KNO} \text { tekanan }-5 \text { bar } \\ & \mathrm{b}_{6}=\mathrm{KNO}_{3} \text { tekanan }-10 \text { bar } \\ & \mathrm{b}_{7}=\text { abu gosok } \\ =\quad & \text { Interaksi perlakuan } \\ & \text { Kesalahan percobaan }\end{aligned}$


Analisis data menggunakan program SAS (1985) melalui Uji F (Anova). Apabila uji F nyata maka dilanjutkan dengan uji berganda Duncan. Variabel pengamatan terdiri dari : daya berkecambah (DB), keserempakan $\left(\mathrm{KS}_{\mathrm{t}}\right)$ dan kecepatan tumbuh $\left(\mathrm{KC}_{\mathrm{t}}\right)$.

\section{HASIL DAN PEMBAHASAN}

Kadar air benih kesambi mengalami penurunan secara gradual selama periode konservasi. Berturut-turut nilai kadar air pada periode konservasi 0,4,8 dan 12 minggu, masing-masing sebesar : 13.00, 8.57, 7.53 dan 7.23\%. Berdasarkan sidik (Tabel 1), interaksi perlakuan berpengaruh nyata terhadap daya berkecambah, keserempakan dan kecepatan tumbuh benih kesambi.

Priming-matriconditioning dengan abu gosok merupakan perlakuan terbaik dalam meningkatkan kapasitas perkecambahan; nilai semua variabel perkecambahan lebih tinggi dan berbeda nyata dibandingkan perlakuan lainnya (Tabel 2). Keberhasilan priming-matriconditioning sangat ditentukan oleh sifat bahan, yaitu memiliki daya pegang air tinggi, sistem pengantaran yang dapat diduga (predictable delivery system), kerapatan ruang yang besar serta sifat mencampur yang baik (Khan et al., 1990). Butiran abu gosok berukuran sangat kecil, yaitu $<600 \mu \mathrm{m}$ sehingga mampu membungkus kulit terluar (testa) secara penuh atau memiliki luas permukaan yang relatif besar (Zanzibar dan Mokodompit, 2007). Struktur kulit benih kesambi yang permeabel dan relatif keras memungkinkan benih terimbibisi secara bertahap pada kapasitas sesuai dan kondisi ini menguntungkan embrio untuk berkembang hingga mencapai fase akhir priming.

Priming-osmoconditioning menggunakan PEG dan $\mathrm{KNO}_{3}$ berpengaruh buruk terhadap perkecambahan. Selain kapasitas kebutuhan air yang belum sesuai, dapat pula disebabkan oleh sifat racun senyawa. Menurut Bradford (1988), PEG memiliki bobot molekul yang besar cenderung tidak meresap dalam benih dibanding dengan $\mathrm{KNO}_{3}$ atau $\mathrm{H}_{2} \mathrm{O}$ yang memiliki bobot molekul relatif kecil. Pada beberapa keadaan, penggunaan PEG dan $\mathrm{KNO}_{3}$ dapat menghambat perkecambahan. Menurut Haigh dan Barlow (1987), efektivitas dan keberhasilan perlakuan priming-osmoconditioning, dipengaruhi oleh faktor suhu, tekanan osmotik larutan, lama imbibisi, jenis benih dan mutu benih yang digunakan. Selain faktor-faktor tersebut, perlakuan priming harus mempertimbangkan tingkat kekerasan kulit (Zanzibar dan Mokodompit, 2007); kulit benih yang relatif keras dan berkayu, lebih sesuai menggunakan perendaman, sedangkan pada kulit bergabus dan mudah rusak dengan cara pelembaban.

Beberapa benih tanaman membutuhkan potensial air pada kisaran suhu kamar ( $\Psi=0$ bar) (Leubner, 2006) untuk perkecambahannya. Potensial air pada kisaran tersebut pada penelitian ini kurang lebih sama dengan perlakuan hidrasi-dehidrasi; respon benih terhadap perlakuan ini lebih baik dari pada tanpa priming. Proses hidrasi - dehidrasi lebih banyak berperan dalam mengaktifkan mekanisme penyembuhan diri dari kerusakan fisiologis dan kemunduran secara alami (Schmidt, 2000). Penelitian yang dilakukan oleh Sur et al. (1998), pada benih Alianthus exelsa yang disimpan selama 3 bulan memiliki kadar air 14\%, kemudian direndam (hidrasi) selama 48 jam diperoleh kadar air $62 \%$. Benih kemudian dikeringkan selama 72 jam pada suhu kamar, hingga kadar airnya turun kembali menjadi 14\%. Perlakuan ini akan melipatduakan ( $2 \mathrm{x}$ ) kecepatan perkecambahan dibanding kontrol (13\% menjadi $26 \%)$. 
Tabel(Table) 1. Sidik ragam pengaruh periode konservasi dan priming terhadap daya berkecambah, keserempakan dan kecepatan tumbuh benih kesambi (Analysis of variance the influence of temporary storage periods and priming on germination precentage, uniformity and germination rate of kesambi seed)

\begin{tabular}{|c|c|c|c|c|}
\hline $\begin{array}{l}\text { Sumber Keragaman } \\
\text { (Source of variance) }\end{array}$ & $\begin{array}{l}\text { Derajat Bebas } \\
\text { (Degree of } \\
\text { freedom) }\end{array}$ & $\begin{array}{l}\text { Jumlah Kuadrat } \\
\text { (Sum square) }\end{array}$ & $\begin{array}{l}\text { Kuadrat Tengah } \\
\text { (Mean square) }\end{array}$ & $\begin{array}{l}\text { F-hit } \\
(F \text { cal })\end{array}$ \\
\hline \multicolumn{5}{|c|}{ Daya berkecambah (DB)/Germination precentage } \\
\hline Periode konservasi (A) & 3 & 7578.1007 & 2526.0336 & $49.71 * *$ \\
\hline Priming (B) & 6 & 24506.0869 & 4084.3478 & $80.38^{* *}$ \\
\hline Interaksi (AxB) & 18 & 1652.8083 & 91.8227 & $1.81^{*}$ \\
\hline Galat & 55 & 2794.6667 & 50.8121 & \\
\hline Total & 82 & 36531.6627 & & \\
\hline \multicolumn{5}{|c|}{ Keserempakan tumbuh $\left(\mathrm{KS}_{\mathrm{t}}\right) /$ Uniformity } \\
\hline Periode konservasi (A) & 3 & 6040.7084 & 2013.5695 & $49.70 * *$ \\
\hline Priming (B) & 6 & 19536.6794 & 3256.1132 & $80.37 * *$ \\
\hline Interaksi $(\mathrm{AxB})$ & 18 & 1317.7506 & 73.2084 & $1.81^{*}$ \\
\hline Galat & 55 & 2228.2045 & 40.5128 & \\
\hline Total & 82 & 29123.3429 & & \\
\hline \multicolumn{5}{|c|}{ Kecepatan tumbuh $\left(\left(\mathrm{KC}_{\mathrm{t}}\right) /\right.$ Germination rate } \\
\hline Periode konservasi (A) & 3 & 3.1238 & 1.04127591 & $85.67 * *$ \\
\hline Priming $(\mathrm{B})$ & 6 & 7.6144 & 1.26907411 & $104.42 * *$ \\
\hline Interaksi $(\mathrm{AxB})$ & 18 & 0.7251 & 0.04028360 & $3.31 * *$ \\
\hline Galat & 54 & 0.6563 & 0.01215401 & \\
\hline Total & 81 & 12.1197 & & \\
\hline
\end{tabular}

Keterangan (Notes) : ** = berpengaruh sangat nyata (highly significantly different), $\mathrm{P}=99 \% *=$ berpengaruh nyata (significantly difference), $\mathrm{P}=95 \%$ 
Tabel(Table) 2. Uji beda Duncan pengaruh periode konservasi dan priming terhadap perkecambahan benih kesambi/prosentase peningkatan atau kehilangan potensi perkecambahan (Duncan test of influence of temporary storage periods and priming for several respons of kesambi seed germination/precentage of increasing or loss germination potential)

\begin{tabular}{|c|c|c|c|c|c|c|c|}
\hline \multirow{2}{*}{$\begin{array}{c}\text { Periode } \\
\text { konservasi } \\
\text { (minggu)/ } \\
\text { Conservation } \\
\text { periods } \\
\text { (weeks) }\end{array}$} & \multicolumn{7}{|c|}{ Nilai parameter perlakuan / The value of variable treatments } \\
\hline & $\begin{array}{c}\text { Tanpa } \\
\text { priming/ } \\
\text { without } \\
\text { priming }\end{array}$ & $\begin{array}{l}\text { Hidrasi- } \\
\text { dehidrasi/ } \\
\text { hydration- } \\
\text { dehydration }\end{array}$ & $\begin{array}{l}\text { PEG } \\
-5 \text { bar }\end{array}$ & $\begin{array}{l}\text { PEG } \\
-10 \text { bar }\end{array}$ & $\begin{array}{l}\mathrm{KNO}_{3} \\
-5 \text { bar }\end{array}$ & $\begin{array}{c}\mathrm{KNO}_{3} \\
-10 \mathrm{bar}\end{array}$ & $\begin{array}{l}\text { abu gosok/ } \\
\text { kitchen ash }\end{array}$ \\
\hline \multicolumn{8}{|c|}{ Daya berkecambah (DB)/Germination precentage (\%) } \\
\hline 0 & $\begin{array}{r}34.67 \mathrm{fg} / \\
0.00\end{array}$ & $\begin{array}{r}36.00 \mathrm{efg} / \\
+1.33\end{array}$ & $\begin{array}{r}21.33 \mathrm{hji} / \\
-13.34\end{array}$ & $\begin{array}{r}9.33 \mathrm{kj} / \\
-25.34\end{array}$ & $\begin{array}{r}8.00 \mathrm{kj} / \\
-26.67\end{array}$ & $\begin{array}{l}4.00 \mathrm{k} / \\
-30.67\end{array}$ & $\begin{array}{r}45.33 \mathrm{efdc} / \\
+10.66\end{array}$ \\
\hline 4 & $\begin{array}{r}40.00 \mathrm{efd} / \\
0.00\end{array}$ & $\begin{array}{r}41.33 \mathrm{e} \mathrm{f} \mathrm{d} / \\
+1.33\end{array}$ & $\begin{array}{r}25.33 \mathrm{hgi} / \\
-14.67\end{array}$ & $\begin{array}{r}12.00 \mathrm{kj} / \\
-28.00\end{array}$ & $\begin{array}{r}8.00 \mathrm{kj} / \\
-32.00\end{array}$ & $\begin{array}{l}5.33 \mathrm{k} / \\
-34.67\end{array}$ & $\begin{array}{r}50.67 \mathrm{bdc} / \\
+10.67\end{array}$ \\
\hline 8 & $\begin{array}{r}49.33 \mathrm{edc} / \\
0.00\end{array}$ & $\begin{array}{r}46.67 \mathrm{efdc} / \\
-2.66\end{array}$ & $\begin{array}{r}33.33 \mathrm{hfg} / \\
-16.00\end{array}$ & $\begin{array}{r}17.33 \mathrm{kji} / \\
-32.00\end{array}$ & $\begin{array}{r}10.67 \mathrm{kj} / \\
-38.66\end{array}$ & $\begin{array}{r}8.00 \mathrm{kj} / \\
-41.33\end{array}$ & $\begin{array}{r}56.00 \mathrm{bac} / \\
+6.67\end{array}$ \\
\hline 12 & $\begin{array}{r}62.67 \mathrm{ba} / \\
0.00 \\
\end{array}$ & $\begin{array}{r}68.00 \mathrm{a} / \\
+5.33 \\
\end{array}$ & $\begin{array}{r}54.67 \mathrm{bc} / \\
-8.00 \\
\end{array}$ & $\begin{array}{r}36.00 \mathrm{efg} / \\
-26.67 \\
\end{array}$ & $\begin{array}{r}38.67 \mathrm{efd} / \\
-24.00 \\
\end{array}$ & $\begin{array}{r}8.00 \mathrm{kj} / \\
-54.67 \\
\end{array}$ & $\begin{array}{r}68.00 \mathrm{a} / \\
+5.33 \\
\end{array}$ \\
\hline \multicolumn{8}{|c|}{ Keserempakan tumbuh $\left(\mathrm{KS}_{\mathrm{t}}\right) /$ Uniformity $(\%)$} \\
\hline 0 & $\begin{array}{r}30.95 \mathrm{fg} / \\
0.00\end{array}$ & $\begin{array}{r}32.14 \mathrm{efg} / \\
+1.19\end{array}$ & $\begin{array}{r}19.05 \mathrm{hji} / \\
-11.9\end{array}$ & $\begin{array}{r}8.33 \mathrm{kj} / \\
-22.62\end{array}$ & $\begin{array}{r}7.40 \mathrm{kj} / \\
-23.55\end{array}$ & $\begin{array}{r}3.57 \mathrm{k} / \\
27.38\end{array}$ & $\begin{array}{r}40.47 \mathrm{efdc} / \\
+9.52\end{array}$ \\
\hline 4 & $\begin{array}{r}35.71 \mathrm{efd} / \\
0.00\end{array}$ & $\begin{array}{r}36.90 \mathrm{efd} / \\
+1.19\end{array}$ & $\begin{array}{r}22.62 \mathrm{hgi} / \\
-13.09\end{array}$ & $\begin{array}{r}10.71 \mathrm{kj} / \\
-25.00\end{array}$ & $\begin{array}{r}7.40 \mathrm{kj} / \\
-28.31\end{array}$ & $\begin{array}{r}4.76 \mathrm{k} / \\
-30.95\end{array}$ & $\begin{array}{r}45.24 \mathrm{bdc} / \\
+9.53\end{array}$ \\
\hline 8 & $\begin{array}{r}40.05 \mathrm{edc} / \\
0.00\end{array}$ & $\begin{array}{r}41.67 \mathrm{efdc} / \\
+1.62 \\
\end{array}$ & $\begin{array}{r}29.76 \mathrm{hfg} / \\
-10.29\end{array}$ & $\begin{array}{r}15.48 \mathrm{kji} / \\
-24.67 \\
\end{array}$ & $\begin{array}{r}9.52 \mathrm{kj} / \\
-30.53 \\
\end{array}$ & $\begin{array}{r}7.14 \mathrm{kj} / \\
-32.91 \\
\end{array}$ & $\begin{array}{r}50.00 \mathrm{bac} / \\
+9.95\end{array}$ \\
\hline 12 & $\begin{array}{r}59.95 \mathrm{ba} / \\
0.00\end{array}$ & $\begin{array}{r}60.71 \mathrm{a} / \\
+0.76\end{array}$ & $\begin{array}{r}48.81 \mathrm{bc} / \\
11.14\end{array}$ & $\begin{array}{r}32.14 \mathrm{efg} / \\
-27.81\end{array}$ & $\begin{array}{r}34.52 \mathrm{efd} / \\
-25.43\end{array}$ & $\begin{array}{r}7.14 \mathrm{kj} / \\
-52.81 \\
\end{array}$ & $\begin{array}{r}60.71 \mathrm{a} / \\
+0.76 \\
\end{array}$ \\
\hline \multicolumn{8}{|c|}{ Kecepatan tumbuh $\left(\left(\mathrm{KC}_{\mathrm{t}}\right) /\right.$ Germination rate $(\% /$ etmal $)$} \\
\hline 0 & $\begin{array}{r}0.58 \mathrm{efg} / \\
0.00\end{array}$ & $\begin{array}{r}0.73 \mathrm{de} / \\
+25.86\end{array}$ & $\begin{array}{l}0.40 \mathrm{~g} / \\
-31.03\end{array}$ & $\begin{array}{l}0.13 \mathrm{~h} / \\
-77.59\end{array}$ & $\begin{array}{l}0.11 \mathrm{~h} / \\
-81.03\end{array}$ & $\begin{array}{r}0.04 \mathrm{~h} / \\
93.10\end{array}$ & $\begin{array}{r}0.71 \mathrm{de} / \\
+22.41\end{array}$ \\
\hline 4 & $\begin{array}{r}0.66 \mathrm{e} / \\
0.00\end{array}$ & $\begin{array}{r}0.78 \mathrm{de} / \\
+18.18\end{array}$ & $\begin{array}{r}0.43 \mathrm{fg} / \\
34.85\end{array}$ & $\begin{array}{l}0.13 \mathrm{~h} / \\
-80.30\end{array}$ & $\begin{array}{r}0.09 \mathrm{~h} / \\
86.36\end{array}$ & $\begin{array}{r}0.05 \mathrm{~h} / \\
92.42\end{array}$ & $\begin{array}{r}0.79 \mathrm{de} / \\
+19.70\end{array}$ \\
\hline 8 & $\begin{array}{r}0.77 \mathrm{de} / \\
0.00\end{array}$ & $\begin{array}{r}0.79 \mathrm{de} / \\
+2.60\end{array}$ & $\begin{array}{r}0.62 \mathrm{fe} / \\
19.48\end{array}$ & $\begin{array}{l}0.20 \mathrm{~h} / \\
-74.03\end{array}$ & $\begin{array}{r}0.12 \mathrm{~h} / \\
84.42\end{array}$ & $\begin{array}{r}0.09 \mathrm{~h} / \\
88.31\end{array}$ & $\begin{array}{r}0.92 \mathrm{dc} / \\
19.48\end{array}$ \\
\hline 12 & $\begin{array}{r}1.15 \mathrm{ba} / \\
0.00\end{array}$ & $\begin{array}{r}1.15 \mathrm{ba} / \\
0.00\end{array}$ & $\begin{array}{r}1.00 \mathrm{bc} / \\
13.04\end{array}$ & $\begin{array}{r}0.71 \mathrm{de} / \\
-38.26 \\
\end{array}$ & $\begin{array}{r}0.74 \mathrm{de} / \\
35.65\end{array}$ & $\begin{array}{r}0.15 \mathrm{~h} / \\
86.96 \\
\end{array}$ & $\begin{array}{r}1.32 \mathrm{a} / \\
14.78 \\
\end{array}$ \\
\hline
\end{tabular}

Keterangan (Notes) : ** = berpengaruh sangat nyata (highly significant difference), $\mathrm{P}=99 \% *$ berpengaruh nyata (significantly difference), $\mathrm{P}=95 \%$.

Semakin lama periode konservasi maka semakin meningkat kapasitas perkecambahan. Nilai kadar air pada masing-masing periode yang terus menurun, serta kapasitas perkecambahan yang terus meningkat hingga 12 minggu mengindikasikan bahwa benih kesambi memiliki dormansi morfologis; tingkat morfologis dari embrio yang belum matang. Menurut Nitsch (1971), proses pematangan buah dan benih biasanya seiring, sehingga kemasakan fisiologis diperoleh pada waktu yang hampir bersamaan. Namun demikian, pada beberapa jenis seperti Ilex opoca dan Fraxinus sp., benihnya memiliki embrio yang tidak berkembang, benih tersebut tidak dapat berkecambah pada saat buah masak tetapi masih memerlukan pemasakan lanjutan. Proses ini sangat berhubungan dengan tahap akhir pematangan, yaitu terhentinya pembentukan cadangan protein dan hormon, namun dehidrasi masih dibutuhkan agar terjadi keseimbangan antara kelembaban udara dengan tingkat kadar air benih serta tahapan perkembangan embrio lebih lanjut. Menurut Bonner et al. (1994), selama proses pematangan, jika benih dikecambahkan meskipun pada kondisi yang menguntungkan akan menghasilkan pertumbuhan awal yang buruk. 
Peran perlakuan priming pada penelitian ini lebih kurang sama dengan perlakuan pendahuluan untuk pematahan dormansi embrio benih. Menurut Bonner et al. (1994), agar terjadi perkecambahan, embrio harus tumbuh maksimum, dan hal ini dimungkinkan oleh perlakuan lembab dan panas yang pada dasarnya merupakan perlakuan pemasakan lanjutan (after ripening). Dengan demikian perlakuan priming yang tepat akan memacu percepatan pertumbuhan embrio. Menurut Leubner (2006), priming adalah perlakuan yang memungkinkan pengontrolan laju imbibisi dan mengaktifkan bahan metabolisme benih untuk memulai proses perkecambahan hingga beberapa waktu sebelum pemunculan radikel, yaitu pada fase akhir priming (activation). Perlakuan hidrasi dihentikan sebelum benih kehilangan toleransi kerusakannya. Benih-benih yang telah mengalami perlakuan priming dapat dikeringkan kembali untuk disimpan, didistribusikan atau di tanam.

\section{KESIMPULAN DAN SARAN}

\section{A. Kesimpulan}

Priming-matriconditioning dengan abu gosok selama periode konservasi merupakan pengkondisian untuk terbaik benih kesambi.

\section{B. Saran}

Agar diperoleh perkecambahan benih kesambi yang optimal, terlebih dahulu dilakukan penyimpanan sementara (12 minggu) kemudian diberikan perlakuan priming untuk menghilangkan dormansi morfologis.

\section{DAFTAR PUSTAKA}

Bailly, C. A. Benamar, F. Corbineau and D. Come. 1998. Free radical scavenging as affected by accelerated ageing and subsequent priming in sunflower seed. Plant Physiol.104:pp 646652.

Bonner, F.T, Vozzo, J.A, Elam W.W and Land, S.B.Jr. 1994. Tree Seed Technology Training Course. Instructors manual. Southern Forest Exp. Station, U.S. Dept. Agric. General Technical Report SO - 106. $160 \mathrm{pp}$.

Bradford, K. J. 1984. Seed Priming. Techniques to speed seed germination. Proceeding of The Oregon Horticultural Society.

Haigh, A. M. and E. W. R. Barlow. 1997. Germination and priming of tomato, carrot, onion and sorghum seed in the range of osmotica. J.Amer. Soc. Hort. Sci

Khan, A.A., H. Miura, J. Prasinki and S. Ilyas. 1990. Matriconditioning of Seed to Improve Emergence. p 19-40. Proceedings of Symposium on Stand Establisment on Holticultural Crop. Minneapolis.

Leubner, G. 2006. The Seed Biology Place. http://www.seed biology.de (Maret, 2007).

Malcolm, B., Wilkins. 1990. Advanced Plant Physiology. Longman scientific and technical. New York. $514 \mathrm{pp}$.

Michel, B.E. 1988. Evaluation of water potentials of polyethylene glycol 6000 both in the absence and presence of other solutes. Plant Physiol.72: pp 66-70.

Murray, A.G. dan D.O. Wilson Jr. 1987. Priming on seed for improved vigor. Bull. Agric. Exp. Station. University of Idaho. 677 : pp 55-77.

Nitsch, J.P. 1971. Perennation through seeds and other structures : Fruit development. In : Plant physiology, a treatise. AP. pp 413 - 501.

Robert, E.H. 1983. Seed Deterioration and Loss of Viability. In : Advances in research and Technology of Seeds. Pudoc, Wageningen. 
SAS Institute Inc. 1985. SAS user's guide: Statistcs, Version 5 edition. SAS Institute Inc., Cary. NC.

Schmidt, L. 2000. Pedoman Penanganan Benih Tanaman Hutan Tropis dan Sub Tropis. Terjemahan. Ditjen RLPs. Departemen Kehutanan. Jakarta. 530 pp.

Sur, K, Lahiri, A.K, Basu, R.N. 1998. Hydration-dehydration treatment for improved storability of bamboo (Dendrocalamus strictus L). Indian Forester 114, pp 560 - 563.

Zanzibar M dan S. Mokodompit, 2007. Pengaruh Perlakuan Hidrasi-Dehidrasi terhadap Berbagai Tingkat Kemunduran Perkecambahan Benih Damar dan Mahoni. Jurnal Penelitian Hutan Tanaman Vol. 4 No.1, Mei 2007. pp 1 - 12. 